\title{
Myocardial ischaemia and defects of atrioventricular conduction associated with cardiac surgery
}

\author{
D. E. M. TAYLOR AND C. F. HIDER \\ From the Department of Thoracic Surgery, Royal Infirmary of Edinburgh
}

Changes in atrioventricular conduction coincident with myocardial anoxia were observed experimentally in the cat over half a century ago (Lewis and Mathison, 1910), but in these experiments the prolongation of atrioventricular conduction time progressing to total atrioventricular dissociation was reversible within a few minutes of restoring full oxygenation. More recent work confirmed the action of myocardial ischaemia or anoxia on cardiac electrical activity and showed that atrioventricular (A-V) nodal conduction was most susceptible to ischaemia (Bagdonas, Stuckey, Piera, Amer, and Hoffman, 1961). In a series of experiments on dogs it has also been noted that after prolonged myocardial ischaemia the recovery of normal atrioventricular conduction was often delayed (Wesolowski, Fisher, Fennessey, Cubiles, and Welch, 1952). Although heart block after cardiac surgery was initially regarded as a serious complication it is not now thought necessarily to carry a grave prognosis, spontaneous recovery often occurring. In a recently reported series of 95 cases of aortic valve replacement total heart block occurred in nine cases, but in only one did it fail to revert spontaneously (Barratt-Boyes, Lowe, Cole, and Kelly, 1965).

We had noted during routine patient monitoring two patients in whom total atrioventricular dissociation occurred before there was any possibility of operative trauma to the A-V node or bundle, and both were associated with an episode of total myocardial ischaemia. We had also noted during open-heart surgery that the recovery of atrioventricular conduction after a single short episode of myocardial ischaemia, as for example with aortic cross-clamping, was complete and rapid; but after frequently repeated episodes of ischaemia the recovery became less rapid and less complete. This observation, if correct, would be compatible with the effect of anoxia on the intracellular action potential of cardiac cells (Trautwein and Dudel, 1956; Kardesch, Hogancamp, and Bing, 1958). So it appeared possible that in man also atrioventricular conduction was more susceptible to anoxia and $\dot{\infty}_{\infty}$ ischaemia than other cardiac electrical activity,

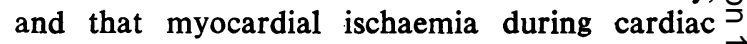
surgery could be a cause of atrioventricular con- $\vec{c}$ duction defects in the immediate post-operative $\stackrel{9}{二}$ phase. Although these would be likely to be spontaneously reversible, and in many cases would $₹$ amount only to a prolongation of the P-R $\vec{\bullet}$ interval, they might yet be a significant adverse $\stackrel{\odot}{V}$ factor in the post-operative period, for it has been 0 shown that cardiac function can be significantly impaired merely by alterations in the normal $\mathbf{P}-\mathbf{R}$ interval (Skinner, Mitchell, Wallace, and Sarnoff, 1963). The present investigations were carried out $\bar{\varnothing}$ to determine whether a possible link exists $\stackrel{2}{\Rightarrow}$ between myocardial ischaemia and defects of atrioventricular conduction after surgery.

\section{METHODS}

Patients undergoing open-heart surgery with cardiopulmonary bypass in the Thoracic Unit of the Edinburgh Royal Infirmary have continuous E.C.G. monitoring during, and for a variable period after, $\hat{\partial}$ surgery. The present series consists of all cases over a period of nine months who underwent open-heart 0 surgery and who before operation were in normal sinus rhythm without conduction defect, minor $\frac{7}{2}$ degrees of bundle branch block being neglected. These were 23 out of the 37 cardiopulmonary bypass $N$ cases in the period. In 14 the heart disease was congenital, and in nine rheumatic, and the ages ranged $\mathrm{O}$ from 8 years to 57 years (see Table). The E.C.G. was recorded by a transistorized amplifier and a mirror $\sigma$ galvanometer photographic recorder, the apparatus having a response flat to $>200$ c.p.s. Records were taken of the unipolar and bipolar limb leads at a $\mathscr{\mathscr { D }}$ paper speed of $100 \mathrm{~mm}$./ sec. and with high amplification to accentuate the wave forms. In every case records of this type were taken shortly after the induc- $\frac{\vec{D}}{\mathbb{D}}$ tion of anaesthesia and after the final skin closure; $\varrho$ additional records were taken at variable times during and after the operation. Measurements were made of $\sigma$ the duration of the $P$ and $Q R S$ deflections and of the 
T A B L E

DETAILS OF AGE, DIAGNOSIS, DURATION OF CORONARY ISCHAEMIA, DEGREE OF HYPOTHERMIA, AND POSTOPERATIVE RHYTHM IN 23 CASES OF OPEN-HEART SURGERY

\begin{tabular}{|c|c|c|c|c|c|c|c|c|c|c|}
\hline \multirow[b]{2}{*}{ Case } & \multirow[b]{2}{*}{ Age } & \multirow[b]{2}{*}{ Diagnosis } & \multirow{2}{*}{$\begin{array}{c}\text { Coronary } \\
\text { Arrest } \\
\text { (min.) }\end{array}$} & \multirow{2}{*}{$\begin{array}{c}\text { Degree } \\
\text { of } \\
\text { Hypo- } \\
\text { thermia }\end{array}$} & \multicolumn{6}{|c|}{ Post-operative Rhythm } \\
\hline & & & & & Normal & $\begin{array}{c}\text { First-degree } \\
\text { Block }\end{array}$ & $\begin{array}{l}\text { Second-de- } \\
\text { gree Block }\end{array}$ & $\begin{array}{c}\text { Third-degree } \\
\text { Block }\end{array}$ & $\begin{array}{l}\text { Long } \\
\mathbf{P}-\mathbf{R}\end{array}$ & Others \\
\hline $\begin{array}{r}1 \\
2 \\
3 \\
4 \\
5 \\
6 \\
7 \\
8 \\
9 \\
10 \\
11 \\
12 \\
13 \\
14 \\
15 \\
16 \\
17 \\
18 \\
19 \\
20 \\
21 \\
22 \\
23\end{array}$ & $\begin{array}{r}32 \\
8 \\
8 \\
18 \\
20 \\
57 \\
37 \\
26 \\
29 \\
12 \\
15 \\
47 \\
13 \\
30 \\
50 \\
11 \\
10 \\
40 \\
57 \\
14 \\
14 \\
9 \\
33\end{array}$ & \begin{tabular}{|} 
A.S.D.(Prim.) \\
V.S.D. \\
v.S.D. \\
A.S.D. (Prim.) \\
v.S.D. +P.S. \\
A.S. \\
A.S. \\
A.S. \\
M.J. \\
V.S.D. \\
V.S.D. \\
A.S. \\
V.S.D.+P.S. \\
M.I. \\
M.I. \\
A.S. \\
A.S. \\
M.I. \\
A.S. \\
A.S.D. (Prim.) \\
V.S.D.+P.S. \\
V.S.D. \\
V.S.D.
\end{tabular} & $\begin{array}{r}9 \\
24 \\
32 \\
30 \\
28 \\
13 \\
9 \\
144 \\
28 \\
18 \\
29 \\
59 \\
38 \\
0 \\
0 \\
28 \\
33 \\
22 \\
86 \\
32 \\
31 \\
42 \\
0\end{array}$ & $\begin{array}{l}\mathbf{M} \\
\mathbf{M} \\
\mathbf{M} \\
\mathbf{M} \\
\mathbf{M} \\
\mathbf{M} \\
\mathbf{D} \\
\mathbf{D} \\
\mathbf{M} \\
\mathbf{M} \\
\mathbf{M} \\
\mathbf{M} \\
\mathbf{M} \\
\mathbf{M} \\
\mathbf{M} \\
\mathbf{D} \\
\mathbf{D} \\
\mathbf{M} \\
\mathbf{D} \\
\mathbf{M} \\
\mathbf{M} \\
\mathbf{M} \\
\mathbf{M}\end{array}$ & $\begin{array}{l}\mathbf{X} \\
\mathbf{X} \\
\mathbf{X} \\
\mathbf{X}\end{array}$ & $\begin{array}{l}X \\
X \\
X\end{array}$ & $\mathbf{x}$ & $\begin{array}{c}X(T r) \\
X \\
X(T r) \\
X\end{array}$ & $\mathbf{x}$ & X (N.T.) \\
\hline
\end{tabular}

${ }^{1}$ In case 14, although there was no coronary ischaemia during the open-heart procedure, there was over 20 minutes' severe hypotension following induction of anaesthesia.

${ }^{2} \mathrm{M}, 32^{\circ}-28^{\circ} \mathrm{C}$.; $\mathrm{D},<23^{\circ} \mathrm{C}$. S.V.T. $=$ Supraventricular tachycardia $;$ N.T. = nodal tachycardia.

P-R interval and the $\mathrm{Q}-\mathrm{T}_{\mathrm{c}}$. In all cases comparisons were made of the same lead, if possible bipolar lead II, at the start and end of the operation. The measurement taken was the mean of five to 10 consecutive cardiac cycles without the occurrence of abnormal complexes.

\section{RESULTS}

A comparison of the records taken immediately after the induction of anaesthesia with those taken at the end of operation showed no change in the duration of the $P$ wave of more than $0.02 \mathrm{sec}$., of the QRS wave of more than 0.04 sec., and of the $\mathrm{Q}-\mathrm{T}_{\mathrm{c}}$ of more than $0.05 \mathrm{sec}$, and all the values on both occasions were within the normal range of variation. There were marked changes in the P-R interval (Fig. 1). In two cases (4 and 10) total heart block developed which was related to trauma to the $\mathrm{A}-\mathrm{V}$ bundle, and these will not be considered further. Of the remaining 21 patients nine showed a definite defect of atrioventricular conduction at the end of operation: three had total A-V dissociation, although in only one was there a slow idioventricular rate ; two had a second degree heart block; and four had a first degree heart block with a $P-R$ interval in excess of $0.2 \mathrm{sec}$. In addition to these nine, two patients developed a paroxysmal arrhythmia, one nodal and the other supraventricular, and two patients showed a prolongation of the $P-R$ interval of more than $0.05 \mathrm{sec}$. as compared with the initial value, though the $P-R$ was less than 0.2 sec. There were no other arrhythmias in the series at the end of operation. Except the one case of supraventricular tachycardia which was treated with digoxin, all the patients spontaneously regained normal conduction. This recovery occurred in from six to 96 hours after operation in all except the case of total heart block with a slow idioventricular rate (case 13), where normal conduction was not fully regained until six weeks after operation. The nine cases of definite heart block were found both in the cases with septal defect, in which there was operative trauma in

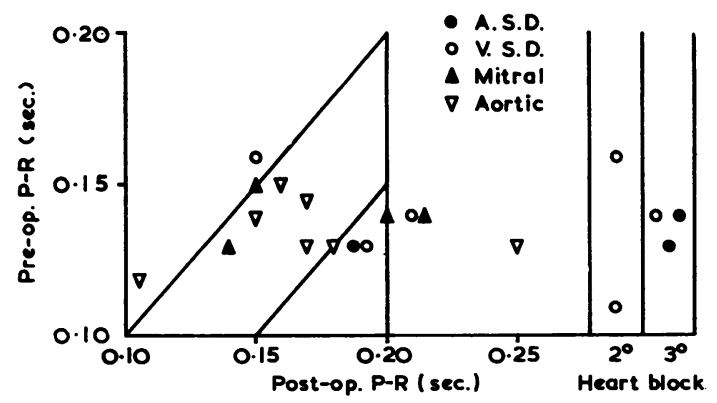

FIG. 1. Comparison of post-induction and post-operative $P-R$ intervals. Note that there is a general tendency to prolongation even in those cases in which clinical heart block does not develop. 


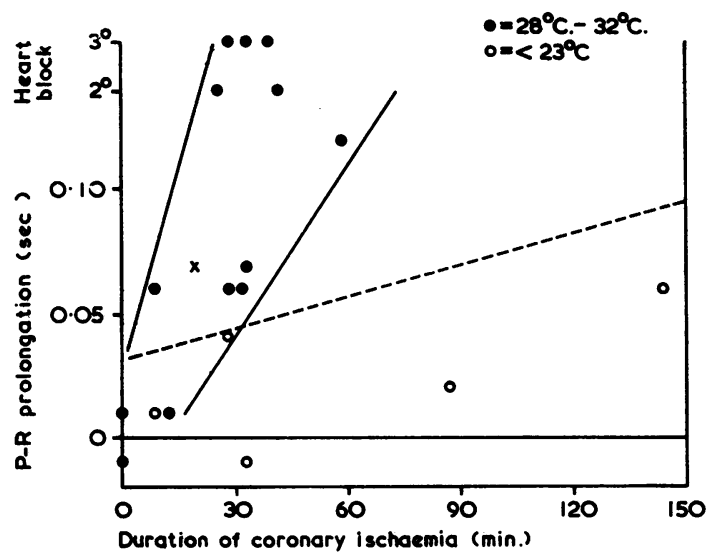

FIG. 2. Relationship between the amount of prolongation of the $P-R$ interval, post-operative as compared to postinductive, and the duration of total myocardial ischaemia. The latter is the total of all episodes of arrested coronary circulation regardless of the duration of perfusion between episodes of arrest. Note the correlation of the duration of ischaemia with the degree of conduction defect. ( $X$-case 14; duration of hypotension at normothermia plotted; there was full coronary perfusion otherwise, see text.)

proximity to the A-V node and bundle, and also in the case of valvular disease, in which the operative procedures were away from areas where direct damage could be caused. Although there was a higher proportion of heart block in the cases of septal defect (six out of 10) than in the cases of valvular disease (three out of 11), this was not mathematically significant ( $\chi^{2}$ test with Yates' correction: $\mathbf{P}=0.3$ ). It was therefore unlikely that $\overline{\bar{\omega}}$ direct trauma to the A-V node or bundle could $\mathbb{D}$ be the cause of conduction defect in every case.

When the incidence of conduction defect was ${ }^{\text {on }}$ compared with the duration of myocardial $\vec{O}$ ischaemia or anoxia a relationship appeared to $\overrightarrow{\vec{\omega}}$ exist (Fig. 2). Of the 15 cases in which the body temperature was lowered to $28-32^{\circ} \mathrm{C}$., in seven $\overrightarrow{\vec{x}}$ there was less than 20 minutes' myocardial ischaemia, and in only one did a conduction? defect develop; but of the remaining eight cases $\vec{\omega}$ in which there was more than 20 minutes' $\infty$

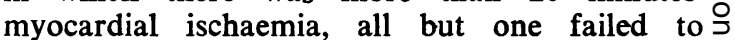
develop a conduction defect. The latter group of $\vec{c}$ eight cases includes one (case 14) in which there was a period of 25 minutes' hypotension, arterial mean pressure $30 \mathrm{~mm} . \mathbf{H g}$ at normothermia, and during this period the P-R interval lengthened $\vec{\varphi}$ from $0.14 \mathrm{sec}$. to $0.22 \mathrm{sec}$. and did not improve despite adequate perfusion and no periods of arrested coronary flow. These results show a significant difference $\left(\chi^{2}\right.$ test with Yates' correction: $0.02>\mathbf{P}>0.01$ ). There appears to be a similar relationship for cases in which deep $\stackrel{\circ}{\circ}$ hypothermia to below $23^{\circ} \mathrm{C}$. was used, but with $\varrho$ a longer 'safe' duration of non-perfusion of the $\overrightarrow{0}$ coronary arteries (Fig. 2).

The prolongation of the P-R interval was progressive, even though in most cases periods of not more than 10 minutes without coronary
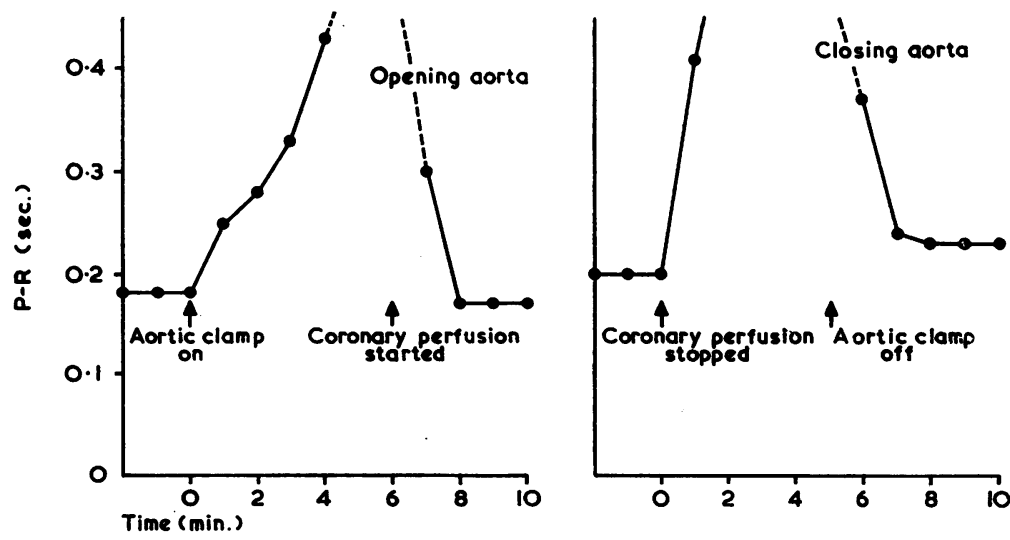

FIG. 3. Case 12. Comparison of the behaviour of atrioventricular conduction during an episode of myocardial ischaemia at the beginning (left) and at the end (right) of an open-heart procedure; 48 min. of myocardial ischaemia in $69 \mathrm{~min}$. between the two records. Note the more rapid deterioration and slower recovery by the end of the procedure, also the lengthened $\boldsymbol{P}-\boldsymbol{R}$, and incomplete recovery at the end. 
perfusion were alternated with periods of one to two minutes with coronary perfusion. It was confirmed that with repeated episodes of myocardial ischaemia atrioventricular dissociation developed more rapidly on stopping coronary perfusion, and after restoring adequate coronary perfusion normal conduction returned more slowly and less completely (Fig. 3).

A typical case (case 12) was that of a man aged 47 years with calcific aortic stenosis treated by debridement at a body temperature of $30^{\circ} \mathrm{C}$. At the start of the valve procedure the aorta was cross-clamped and opened, and separate coronary artery perfusion through cannulae was established after six minutes. During this time the E.C.G. slowly deteriorated, but complete A-V dissociation did not occur until almost five minutes after cross-clamping and reverted within two minutes of coronary perfusion to the pre-clamping $\mathrm{P}-\mathrm{R}$ duration. During the debridement coronary perfusion was interrupted intermittently for from three to eight minutes at a time, with from onehalf to 10 minutes' perfusion between; so that during a period of 78 minutes there was total myocardial ischaemia for 59 minutes. At the end of the debridement the P-R interval had lengthened by $0.03 \mathrm{sec}$. The aorta was then sutured, which necessitated a further five minutes without coronary perfusion.,During this period complete A-V dissociation occurred within two minutes, and on release of the aortic clamp it was two minutes before complete dissociation had reverted, and after five minutes, when rewarming started, the $\mathbf{P}-\mathbf{R}$ interval was prolonged by a further $0.03 \mathrm{sec}$. At the end of the operation the patient was in first-degree heart block, with a P-R of 0.25 sec., and this slowly returned to the pre-operative duration of $0 \cdot 13 \mathrm{sec}$. over the next 12 hours.

\section{DISCUSSION}

Despite the apparently high incidence of conduction defects immediately following surgery in this series, in only two cases (cases 11 and 22) was the degree of arrhythmia sufficient to be readily detectable and to cause obvious cardiac dysfunction. One was the only one of the three cases of total heart block with a slow idioventricular rate, and the other was a second degree heart block with an irregular pattern. But a significant haemodynamic disturbance would probably be produced in more than these two cases; possibly indeed in all nine out of twenty-one. It has been shown that increase in the duration of the $P-R$ interval without normal limits can impair cardiac performance, with a rise in left atrial diastolic pressure and a fall in cardiac output (Skinner, Mitchell, Wallace, and Sarnoff, 1963). Changes of this type could produce' adverse effects on a heart in or near to failure, particularly in the first few days after operation. If this is so the factors which may give rise to minor as well as to major degrees of conduction defect must be determined and as far as possible eliminated in the course of cardiac surgery.

From consideration of the results of this series it is most unlikely that damage to the region of the A-V node or bundle is the single common factor in producing conduction defects, although it is undoubtedly a factor in some cases and must therefore be guarded against. There does, however, appear to be evidence that in man atrioventricular conduction is especially sensitive to anoxia or ischaemia, as reported in other species (Wesolowski, Fisher, Fennessey, Cubiles, and Welch, 1952), and that this can be progressive even if a short period of normal coronary circulation is allowed between episodes of ischaemia. The latter observation would correspond to previous observations (Trautwein and Dudel, 1956; Kardesch et al., 1958) on the effect of anoxia on the intracellular electrical activity and contractility of cardiac cells; for although the latter recovers rapidly when full oxygenation is restored, the former recovers more slowly and both show progressively slower recovery with increasing duration of anoxia. Indeed in the cat papillary muscle, after 30 minutes' anoxia, the mechanical activity has returned almost to initial values in five minutes, but the electrical activity takes 20 minutes to return to normal. The anatomical level at which this defect occurs cannot be accurately assessed from these results but is likely to be near to the level of transmission of the impulse from the atrial myocardium to the head of the A-V node; for in two out of the three cases of total A-V dissociation a fast 'idioventricular' rhythm was established, and from electrophysiological observations the intrinsic rhythmicity decreases in rate as one proceeds from the node and bundle to the Purkinje network (Scher, 1962). This level of block has also been postulated in a report of dog experiments on anoxic block (Bagdonas et al., 1961). Conduction defects following a short period of cardiac arrest have been shown to be due to the ionic shifts consequent on metabolic acidosis, and are rapidly reversible on restoring normal hydrogen ion balance (Stewart, 1965). The conduction defects 
following prolonged or repeated myocardial ischaemia reported in this series differ from the former in not being rapidly reversible in the presence of a normal hydrogen ion balance; yet their behaviour in mecovering spontaneously, though slowly, suggests a biochemical disturbance. The results reported do not permit any speculation as to the nature of this proposed disturbance, but previous workers have reported myocardial anoxia causing ATP depletion and disturbance of the 'sodium pump' mechanism (Trautwein and Dudel, 1956 ; Danforth, Naegle, and Bing, 1960).

Since atrioventricular conduction defects appear more rapidly and depart more slowly with each episode of myocardial ischaemia, it appeared that either or both of two modifications were indicated in the technique of intermittent coronary perfusion. First, the safe period of coronary ischaemia should be progressively reduced, and secondly the duration of coronary perfusion between episodes of coronary ischaemia should be progressively increased. The latter should, if possible, be judged on the E.C.G. record rather than on the appearance of the mechanical activity of the heart, and as much attention should be paid to the duration of the $\mathbf{P}-\mathbf{R}$ interval as to changes in the $S-T$ segment and the $T$ wave. Both measures have been adopted in the year since this investigation was completed, and in an average perfusion of 30 to 60 minutes' duration the spells of myocardial ischaemia are gradually reduced to half, and the periods of coronary perfusion are increased under E.C.G. control or, if this is not possible, are gradually increased to double their initial duration. With this procedure the incidence of all grades of conduction defect has been reduced to a low level; but if for any reason there is prolonged or frequent myocardial ischaemia, conduction defects occur in frequency and intensity similar to those reported in this series.

\section{SUMMARY}

Twenty-three cases of open-heart surgery performed on patients in normal sinus rhythm pre-operatively are reported; in two traumatic heart block developed, and in nine others conduction defects of uncertain aetiology. Of the latter, four were first degree, two were second degree, and three were total A-V dissociation. They appeared to be related to the duration of coronary ischaemia rather than to any other factor, and were progressive throughout the openheart procedure. All these defects recovered spontaneously in six to 96 hours. It is considered that myocardial ischaemia is a contributory factor to post-operative conduction defects, which, however slight, are likely to have a deleterious effect on cardiac function. A method of controlling techniques involving intermittent coronary perfusion has been developed so as to minimize the occurrence of post-operative cardiac conduction defects. Attention should be paid during operation to the susceptible electrical activity of the heart rather than to the more resistant mechanical activity.

We wish to thank Mr. A. Logan and the surgeons of the Thoracic Surgical Unit for their co-operation. The costs of this research were covered under a grant from the Scottish Hospital Endowment Research Trust. to whom we also express our thanks.

\section{REFERENCES}

Bagdonas, A. A.. Stuckey, J. H., Piera, J., Amer, N. S., and Hoffman B. F. (1961). Effects of ischemia and hypnoxia on the specialized conducting system of the canine heart. Amer. Heart J., 61, 206.

Barratt-Boyes, B. G., Lowe, J. B., Cole, D. S., and Kelly, D. T. (1965). Homograft valve replacement for aortic valve disease. Thorax, 20, 495 .

Danforth, W. H., Naegle, S., and Bing, R. J. (1960). Effects of ischemia and reoxygenation on glycolytic reactions and adenosinetriphosphate in heart muscle. Circulat. Res., 8, 965.

Kardesch, M., Hogancamp, C. E., and Bing, R. J. (1958). The effect of complete ischemia on the intracellular electrical activity of the whole mammalian heart. Ibid., 6, 715.

Lewis, T., and Mathison, G. C. (1910). Auriculo-ventricular heart block as a result of asphyxia. Heart, 2, 47.

Scher, A. M. (1962). Excitation of the heart, In American Handbook of Physiology, Section 2: Circulation, Volume 1, ed. W'. F. Hamilton and P. Dow, p. 287. Williams and Wilkins, Baltimore

Skinner, N. S., Jr., Mitchell, J. H., Wallace, A. G., and Sarnoff, S. J. (1963). Hemodynamic effects of altering the timing of atrial systole. Amer. J. Physiol., 205, 499.

Stewart, J. S. S. (1965). Advances in the management of cardiac arrest. J. rov. Coll. Surg. Edinb., 10, 85.

Trautwein, W., and Dudel, J. (1956). Aktionspotential und Kontraktion der Ḧerzmaskels in Sauerstoffmangf. Pflügers Arch. ges. Physiol., 263, 23.

Wesolowski, S. A., Fisher, J. H., Fennessey, J. F., Cubiles, R., and Welch, C. S. (1952). Recovery of the dog's heart after varying periods of acute ischemia. In Surg. Forum (38th Clinical Congress), p. 270. Saunders, Philadelphia. 